\title{
Renewable Energy Storage \& its Application for Desalination
}

\author{
Muhammad Wakil Shahzad ${ }^{1}$, Muhammad Burhan ${ }^{1}$, Kim Choon Ng${ }^{1}$ \\ ${ }^{1}$ Water Desalination and Reuse Centre (WDRC), \\ Biological and Environmental Science \& Engineering (BESE), \\ King Abdullah University of Science and Technology, Saudi Arabia \\ Email: muhammad.shahzadekaust.edu.sa
}

\begin{abstract}
The economic development has serious impact on the nexus between water, energy and environment. This impact is even more sever in Non Organization for Economic Cooperation and Development (non-OECD) countries due to improper resource management. It is predicted that energy demand will increase more than $71 \%$ in non-OECD as compared to $18 \%$ in developed countries by 2040. In Gulf Cooperation Council countries, water and power sector consume almost half of primary energy produced. In the past, many studies were focused on renewable energies based desalination processes to accommodate 5 fold increase in demand by 2050 but they were not commercialized due to intermittent nature of renewable energy such as solar and wind. We proposed highly efficient energy storage material, Magnesium oxide $(\mathrm{MgO})$, system integrated with innovative hybrid desalination cycle for future sustainable water supplies. The condensation of $\mathrm{Mg}(\mathrm{OH})_{2}$ dehydration vapor during day operation with concentrated solar energy and exothermic hydration of $\mathrm{MgO}$ at night can produce 24 hour thermal energy without any interruption. It was showed that, $\mathrm{Mg}(\mathrm{OH})_{2}$ dehydration vapor condensation produce $120^{\circ} \mathrm{C}$ and $\mathrm{MgO}$ hydration exothermic reaction produce $140^{\circ} \mathrm{C}$ heat during day and night operation respectively correspond to energy storage of $81 \mathrm{~kJ} / \mathrm{mol}$ and $41 \mathrm{~kJ} / \mathrm{mol}$. The produced energy can be utilized to operate desalination cycle to reduce $\mathrm{CO}_{2}$ emission and to achieve COP21 goal. The proposed hybrid desalination cycle is successfully demonstrated by pilot experiments at KAUST. It was showed that $\mathrm{MgO}+\mathrm{MEDAD}$ cycle can achieve performance over $\mathrm{UPR}=200$, one of the highest reported ever.
\end{abstract}

Keywords: Thermal desalination, Adsorption cycle, Hybrid cycle, Renewable energy, solar energy, energy storage material. 


\section{Introduction}

Increased water demand and the degradation of water sources is not only threaten the fast economic development activities but also the public health in many developing countries. Particularly, GCC countries are most effected region because of rapid population and development growth and poor water resources management even with limited water resources. In GCC region, per capita renewable water availability is the lowest in the world and they housed 5\% of world population. To meet water demand, all GCC countries heavily relay on desalination processes. The GCC countries started desalination in 1950 to meet their demand and to maintain groundwater resources sustainability and today they hold around $75 \%$ share of world desalination capacities. The change in climate is expected to make this region more water scarier due to high evaporation rate and reduced average rainfall. In addition, the population growth trend coupled with anticipated climate change will pressurize the water situation even more. It is estimated that by 2050 , GCC countries will only able to satisfy $23 \%$ of demand that will yield 26 billion cubic meters $(\mathrm{bcm})$ per year water shortage, $77 \%$ of consumption [1]. Huge desalination capacities are expected to be installed in future to fulfill the water demand. Unfortunately, the conventional desalination process are not only energy intensive but also environment unfriendly. Today's best desalination processes consume 7-10 kWh primary energy to produce one cubic meter of water and emit around 3-4 kg of $\mathrm{CO}_{2}$ emission [2]. The amount of energy required for seawater desalination processes is almost 10 times higher than the river and lake water treatment. This high energy consumption not only results higher water and associated processes cost but also severe environmental impact. Therefore, an improved desalination processes and implementation of alternate energy resources are important for future sustainability.

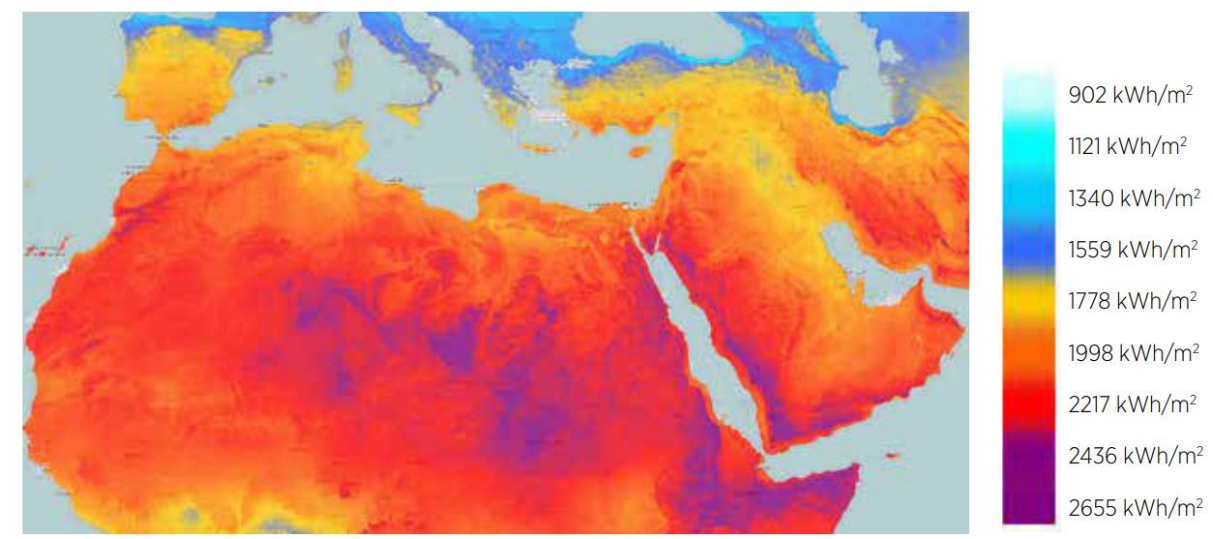

Fig. 1. Solar energy availability in Middle East and North Africa (MENA) region. 
Since renewable energies has no impact on environment, so desalination processes based on these technologies will be more sustainable for future water supplies. In addition, the overall cost of water production will be reduced to very low due to free availability of these energy sources. Renewable energy driven desalination process are in R\&D phase since long and few of them were able to get place in practical application but most of them were not able to commercialize due to large capital cost and intermittent nature of renewable energy. The Sunbelt region, GCC countries, have highest solar irradiance and also available most of the time of the year that can be harnessed to produce portable water through desalination processes in sustainable manner. Figure 1 shows the solar irradiance in GCC region [3].

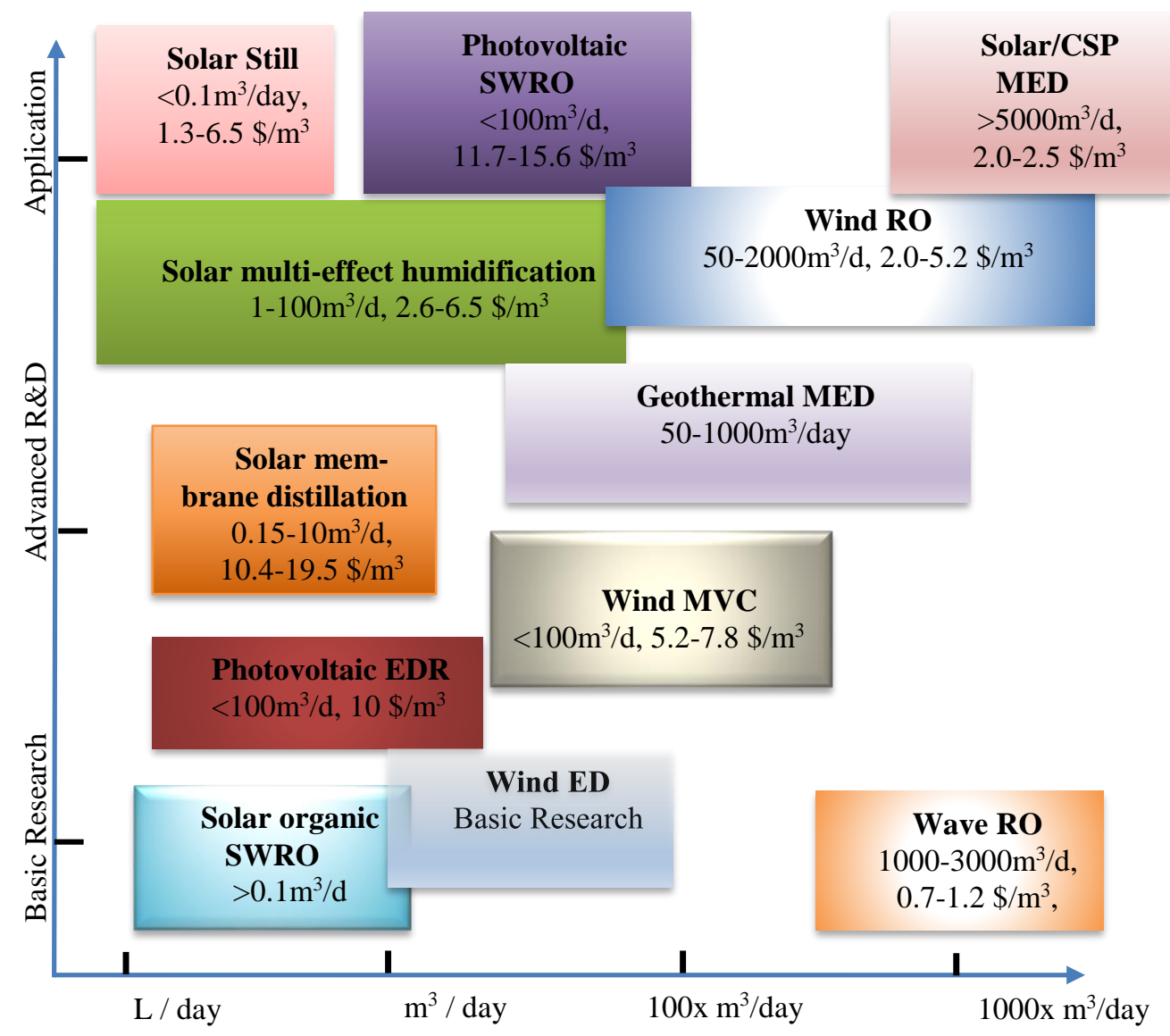

Fig. 2. Renewable energy driven desalination technologies and their status of application with maximum design size. 
Solar energy is an attractive source because firstly its has low operational and capital cost and in addition, it is environmental friendly. Solar energy driven desalination processes are heavily investigated by many researchers for their commercial application possibilities. Some processes are still under research and development phase and some technologies are implemented at certain locations for commercial application. Figure 2 shows the status of desalination processes operating with solar energy. The application chart showed that solar energy based thermally driven desalination processes are implementing at large scale to produce fresh water followed by photovoltaic driven membrane processes [4].

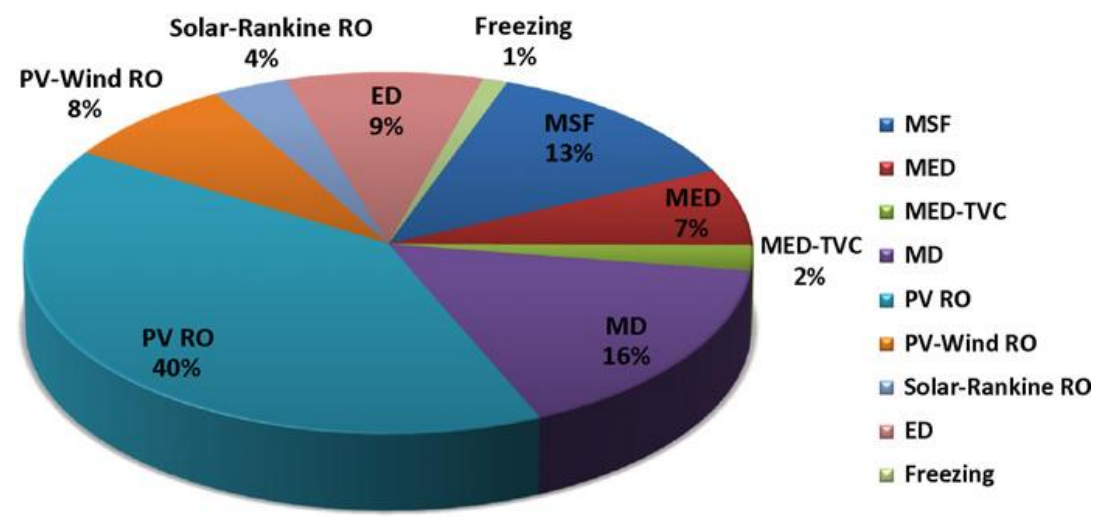

Fig. 3. Share of different desalination processes operating with renewable energy sources.

Even though solar energy is promising for sustainable water production but its intermittent availability is main bottleneck in its major application. Currently, over 130 desalination plants powered by renewable processes contributing only $1 \%$ to total world desalination capacities. The share of different processes is shown in Figure 3 [5]. To increase solar driven desalination capacity, it require energy storage for 24 hours operation.

\section{Solar Thermal Energy Storage Options}

Two main features of solar energy, almost free and endless, make it more attractive as compared to other renewables. However, its cyclic nature is the main hindrance in its commercial applications. To overcome this limitation, scientists proposed solar thermal energy storage (STES) system that can store solar energy as a thermal heat during day time and release when solar radiations are weak or not available. The necessary electricity for equipment operation can be supplied with concentrated solar photovoltaic 
(CSP) system equipment with STES system. The commercial applicability of STES system is depend on its efficiency and cost effectiveness. The STES system can be divided into three classes based on the method of heat storage. These three classes are the sensible heat storage, the latent heat storage and thermochemical heat storage. The efficiency and cost effectiveness of STES system is based on five parameters such as (i) temperature for storage, (ii) period for storage, (iii) storage material availability, (iv) material storage capacity and (v) operation.

The thermochemical heat storage have many advantages such as (i) 5 to 10 times higher energy density as compared to other two STES systems and (ii) minimum losses during storage and transportation. Because of these two properties, these systems can be utilized to store long-term period energy. However, thermochemical heat storage system is still not able to commercialized at large scale and this is one of the reason that there is no trustable data available for application design. The designing of thermochemical heat storage system need careful selection of chemical reaction and detailed investigation of operational parameters such as pressure, temperature, kinetics and reversibility. The main classifications of reactions for thermochemical heat storage system are presented in Figure 4 [4].

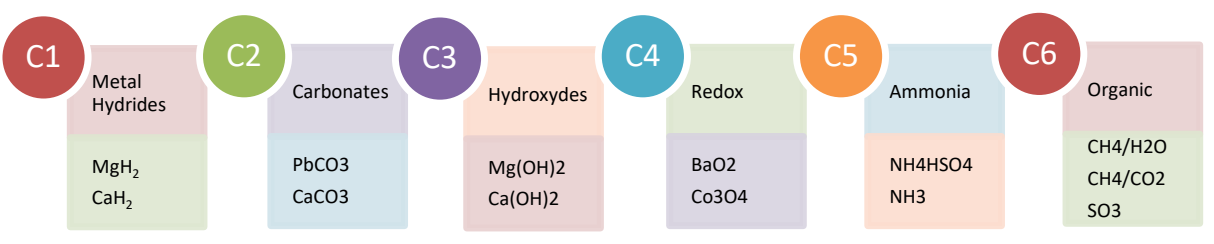

Fig. 4. Main classifications of reactions for thermochemical heat storage system.

A chemical heat pump (CHP) operated with Magnesium oxide and water pair $\left(\mathrm{MgO} / \mathrm{H}_{2} \mathrm{O}\right)$ is considered due to high energy storage capacity and simple operation. The proposed CHP operate on reversible chemical reaction between $\mathrm{MgO}$ and $\mathrm{Mg}(\mathrm{OH})_{2}$ based on the following equilibria. Megnesium oxide has highest energy storage density as compaerd to many other energy storage materials as shown in Figure 5 [5-8].

$$
\begin{array}{cc}
M g O(s)+H_{2} O(g) \leftrightarrow M g(O H)_{2}(s) & \Delta H_{1}=-81.02[\mathrm{KJ} / \mathrm{mol}] \\
H_{2} \mathrm{O}(\mathrm{g}) \leftrightarrow \mathrm{H}_{2} \mathrm{O}(\mathrm{l}) & \Delta H_{1}=-40.66[\mathrm{KJ} / \mathrm{mol}]
\end{array}
$$




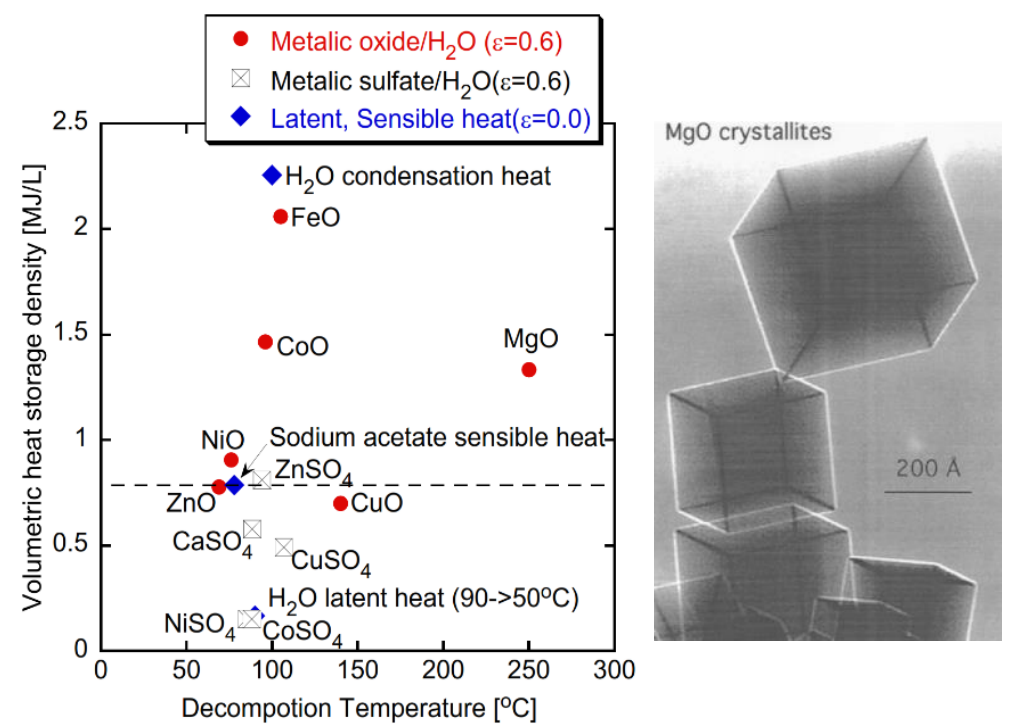

Fig. 5. Energy density of different thermal energy storage materials at different operat-

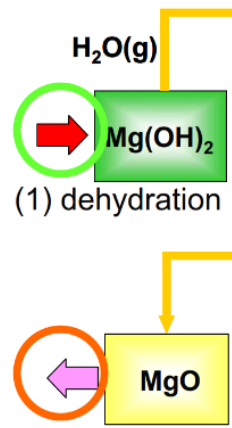

(4) hydration

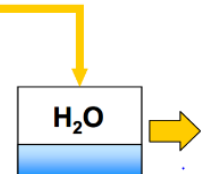

(2) condensation

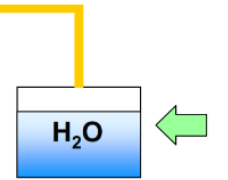

(3) evaporation

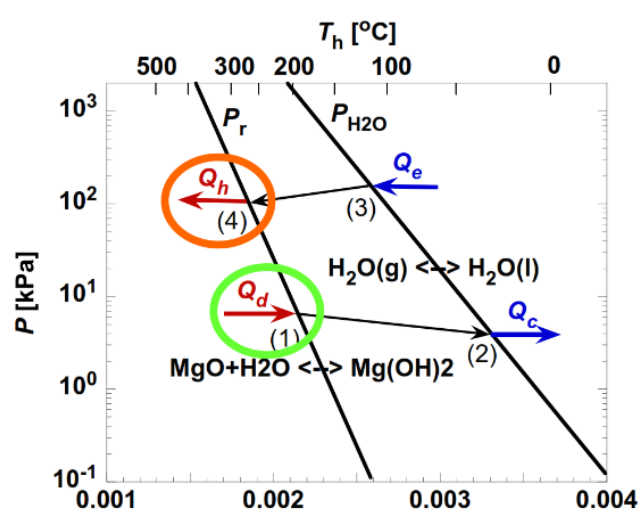

$1 / T[1 / K]$ ing temperatures.

Fig. 6. Energy storage principle of $\mathrm{MgO} / \mathrm{H}_{2} \mathrm{O}$ heat pump.

The operation of proposed CHP system is presented in Figure 6 [9-12]. The two major components are (i) chemical reactor packed with magnesium oxide and (ii) an evaporator filled with water. One complete cycle of operation consist of heat storage mode and heat release mode.

In heat storage mode the fully hydrated magnesium hydroxide $\left(\mathrm{Mg}(\mathrm{OH})_{2}\right)$ is exposed to the concentraed sun at $T_{d}$ to supply heat $\left(Q_{d}\right)$ for dehydration process. The vapours 
produced during dehydration process are condensed at $\mathrm{T}_{\mathrm{C}}$ in the condenser and the condensation heat $\left(\mathrm{Q}_{\mathrm{d}}\right)$ is utilized for desalination cycle at day time during energy storage mode.

In heat release mode hydrated magnesium oxide is exposed to water evaporator to extract vapor for hydration. Since the adsorption is an exothermic reaction so hydration heat $\left(\mathrm{Q}_{\mathrm{h}}\right)$ at $\mathrm{T}_{\mathrm{h}}$ is extracted and utilized during night operation and heat release mode. It can be noticed that there is no major moving parts are involved in operation and this is the major advantage of proposed cycle. In addition, it is environment friendly and also economic because $\mathrm{MgO}$ is easily available. The proposed CHP can store energy at over $300^{\circ} \mathrm{C}$ and deliver over $100^{\circ} \mathrm{C}$ for 24 hour operation. This heat can be utilized for the operation of proposed cycles for cooling and desalination. The detail of proposed cycles, adsorption (AD) cycle for cooling and hybrid multi effect desalination and adsorption cycle (MEDAD) for desalination are presented in the following sections.

\section{STES System and Desalination Cycle}

The proposed system have three major sub-systems, namely; the AD subsystem, the MED subsystem and STES subsystem. The detail of AD subsystem, hybrid MEDAD subsystem and $\mathrm{MgO}+\mathrm{MEDAD}$ is presented in following sections.

\subsection{AD Subsystem}

Low temperature operated adsorption (AD) subsystem is an affordable solution to produce fresh water and cooling using solar thermal energy. Plethora literature is available on $\mathrm{AD}$ cycle investigation for their working pair selection and performance improvement. The basic AD cycle consists of adsorbent beds, evaporator, condenser and liquid circulation pumps. The process schematic is shown in Figure 7. The two main processes for $\mathrm{AD}$ cycle are adsorption-evaporation and desorption-condensation.

In adsorption-evaporation process, the dried adsorbent is exposed to the evaporator to assist evaporation due to adsorbent high affinity for water vapors. Since adsorption is an exothermic process that increase the adsorbent temperature and reduce its adsorption capacity. To maintain adsorption process, coolant is circulated through heat exchanger tubes to extract the heat of adsorption. The evaporator temperature is maintained by circulating the chilled water through the tubes. The AD evaporator can operate at as low as $5^{\circ} \mathrm{C}$ to produce cooling effect when it is operated as a chiller. The adsorbent can adsorb vapors and maintain evaporation process until it get fully saturated. Once adsorbent is fully saturated, it switch process to regeneration to prepare for next operation. 


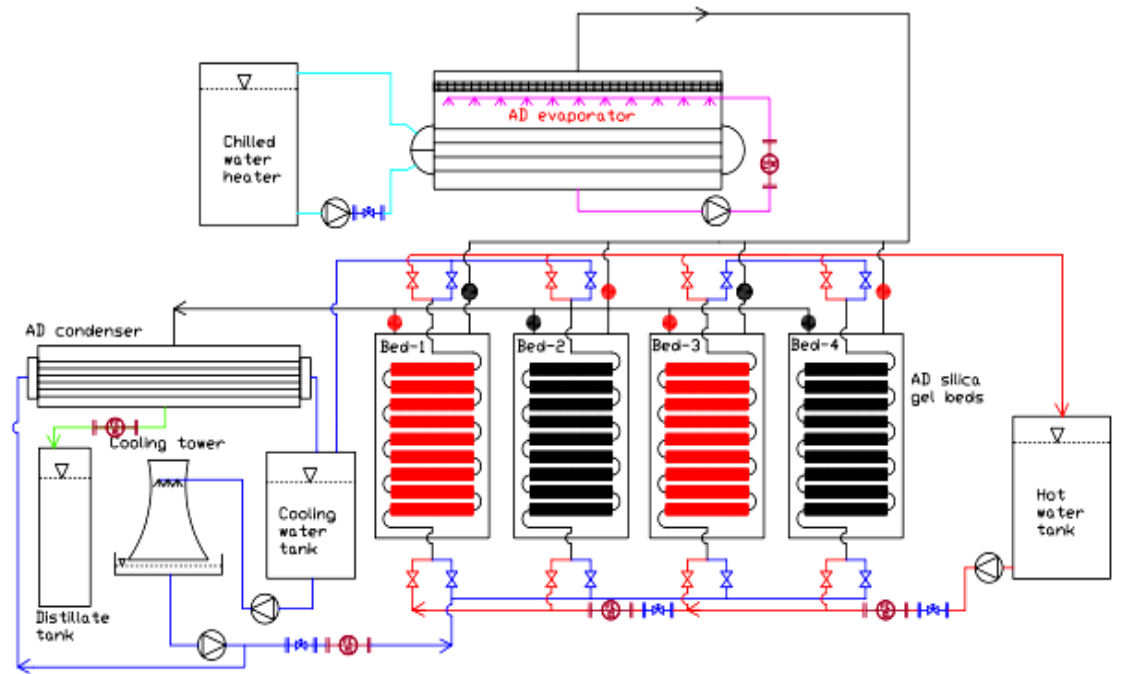

Fig. 7. Basic adsorption subsystem flow schematic.

In desorption-condensation process, low temperature heat source from $55^{\circ} \mathrm{C}$ to $85{ }^{\circ} \mathrm{C}$ is supplied to the reactor bed to regenerate the adsorbent. The regenerated vapors are then condensed in the condenser to produce distillate. When it is operating as a chiller, the refrigerant is refluxed back to the evaporator as a close loop.

To overcome cyclic operation limitations of conventional AD cycle, multi bed system was proposed for continuous operation. The number of beds depend on the size of AD system as per cooling or desalination requirements. In multi bed scheme, they operate as a pair for adsorption and desorption processes. The automatic switching method is applied to switch their duties from adsorption to desorption process to complete cycle. The time for adsorption/desorption process is depend on quantity of adsorbent packed in a single bed. It can be noticed that the major moving parts are just automatic valves and circulation pumps that make $\mathrm{AD}$ cycle very robust and very less maintenance is required. It can produce two useful effect, cooling and desalinated water. 


\subsection{Hybrid MEDAD Desalination Subsystem}

In conventional multi effect desalination (MED) subsystem, the heat source is supplied to the first steam generator and seawater is sprayed on to the tube surfaces. The saturation pressure is controlled to maintain evaporation under vacuum conditions at $65^{\circ} \mathrm{C}$. The vapor produced in the first stage are channeled to the tubes of second stage to reutilize the heat of condensation. The produced vapors are then condensed by transferring the heat condensation to the seawater sprayed that help to evaporate the part of the feed. The condensed vapor produce fresh water that is collected from each stage. This process of evaporation and condensation of feed water and vapors continue until the last stage of the system. The last stage vapors are condensed in the final condenser by circulating the seawater. It can be noticed that the overall operational range for conventional MED system is from heat source temperature $65^{\circ} \mathrm{C}$ to the last stage condenser temperature $40^{\circ} \mathrm{C}$. These operational limitations also limit the performance of thermally driven desalination processes. The performance of desalination processes can be improved by overcoming their operational limitations.

Some studies showed that heat source temperature can be increased to $120^{\circ} \mathrm{C}$ by introducing proper pre-treatment processes to overcome the scaling and fouling chances. Nano-filteration (NF) is one of the pretreatment process that can help to remove soft scaling components from feed water to prevent scaling and fouling chances at high temperature operation.

On the other hand, the proposed hybridization of $\mathrm{AD}$ cycle with conventional MED system can help to overcome last condenser temperature limitations and operation can be extended to as low as $5^{\circ} \mathrm{C}$. The detailed schematic of MEDAD hybrid cycle is is shown in Figure 8 [13-22].

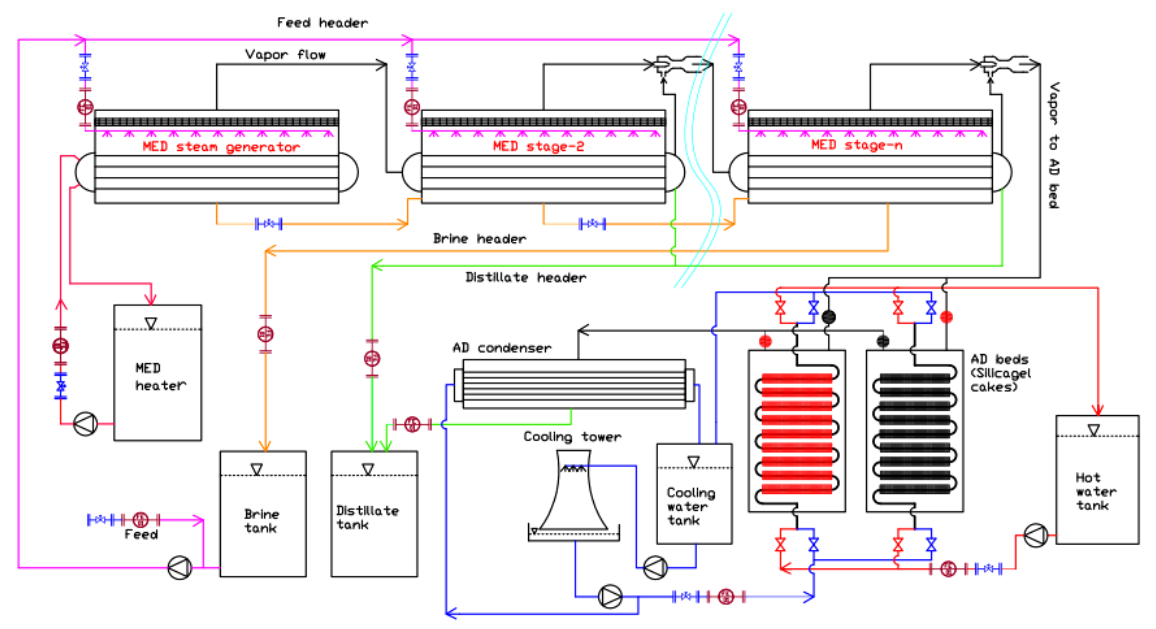

Fig. 8. Hybrid MED+AD desalination subsystem flow schematic. 
In hybrid cycle, the MED last stage condenser is bypassed and vapors are directly adsorbed on the adsorbent of AD cycle. The high affinity of adsorbent toward water vapor reduced saturation pressure and hence temperature. This hybrid cycle extend the temperature range from typical $40^{\circ} \mathrm{C}$ to $5^{\circ} \mathrm{C}$ and it help to insert more number of stags. The more number of stages will help to increase the number of recoveries from provided input and hence performance will improve. It was reported that hybrid MEDAD cycle can boost the water production to two fold as compared to conventional MED system at same heat source temperature. It can be observed that the tri-hybrid system $\mathrm{NF}+\mathrm{MED}+\mathrm{AD}$ can be the best performance system if operated with renewable energy for future sustainability. The proposed trihybrid cycle can be operated with STES system to produce fresh water 24 hours. The detailed of the system is presented in following sections.

\subsection{Proposed MgO+MEDAD Desalination Subsystem}

In this proposed subsystem, $\mathrm{MgO}$ is coated on tubes and module is sized are per energy storage requirement. This energy storage tubes module is connected to a seawater evaporator and a condenser. During day operation, to dehydrated $\mathrm{Mg}(\mathrm{OH})_{2}$, solar rays are concentrated to the module at $300^{\circ} \mathrm{C}$ and desorbed vapors are directed toward the condenser for condensation. The heat produced during condensation is recovered through hot water closed circulation loop to supply heat to MEDAD cycle steam generator or first stage. This process continue until solar energy is available throughout the day.

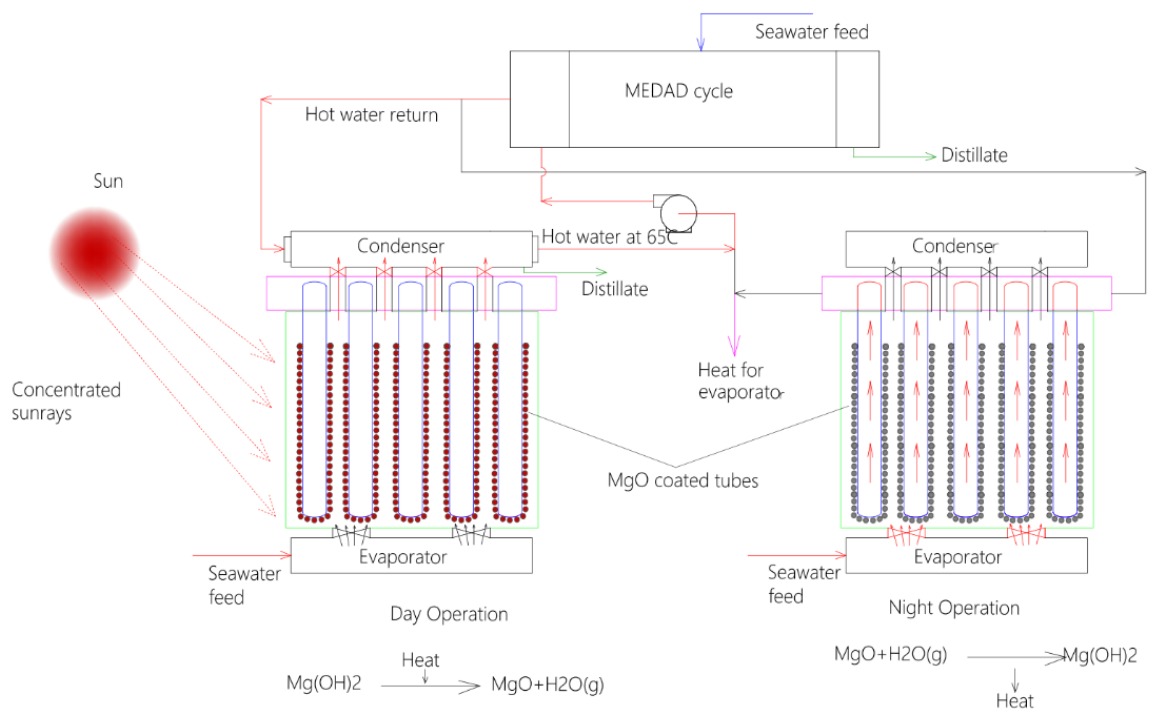

Fig. 9. Proposed $\mathrm{MgO}+\mathrm{MED}+\mathrm{AD}$ desalination subsystem flow schematic. 
After sunset, during night operation, the dried $\mathrm{MgO}$ tubes are exposed to seawater evaporator. The hydration of $\mathrm{MgO}$ is an exothermal process and this heat is recovered from the top head of tubes (acting like heat pipe) and supplied to the first stage of MEDAD cycle. The exothermic heat recovery will not only help to maintain adsorption process but will also help to operate MEDAD cycle at night. The detailed flow schematic of proposed system is shown in Figure 9.

To verify the concept, a pilot was installed at King Abdullah University of Science and Technology (KAUST) and tested successfully. The detail of pilot is presented in following section.

\section{MEDAD Desalination Pilot Experimentation}

To investigate MEDAD operation, a 4-effect pilot was designed and build in KAUST as shown in Figure 10 (a \&b). The pilot capacity is $4 \mathrm{~m}^{3} /$ day as a standalone MED and around $8 \mathrm{~m}^{3} /$ day when operated with combination of Ad cycle as a MEDAD hybrid cycle. The MED pilot is operating with parallel feed system supplied from Red Sea after minimal pretreatment. Due to budget constraint, the heat input was simulated via solar collectors and boiler.

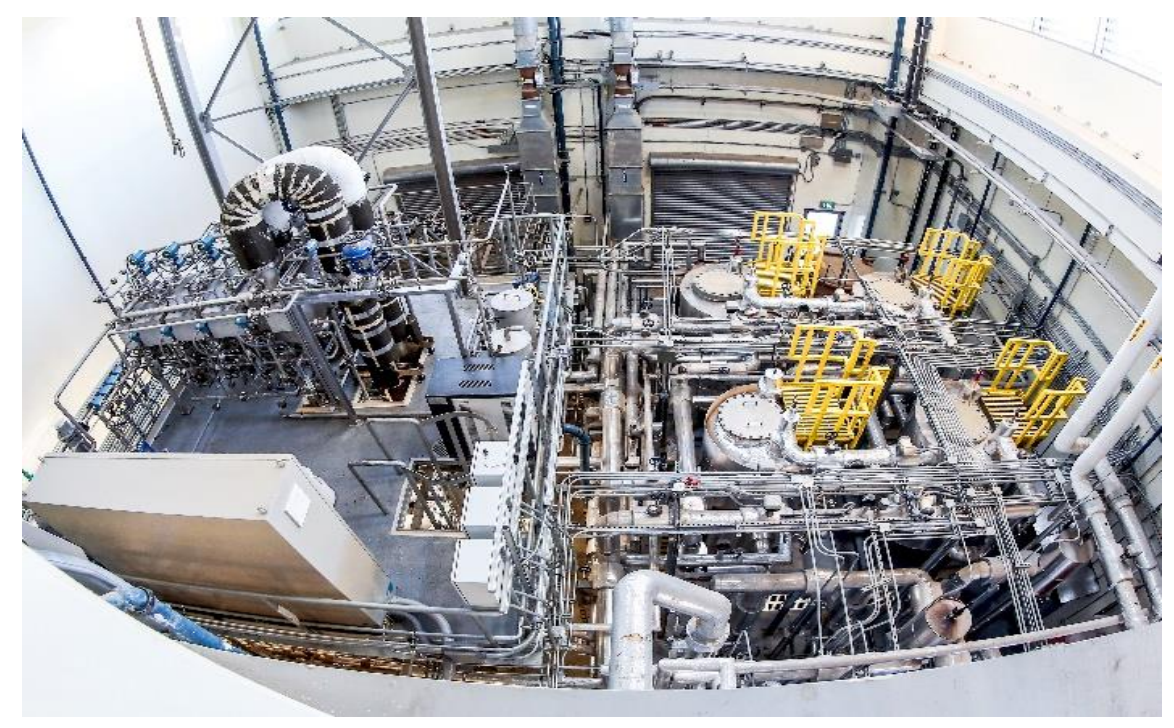

Fig. 10 (a). MEDAD hybrid pilot installed at KAUST. 


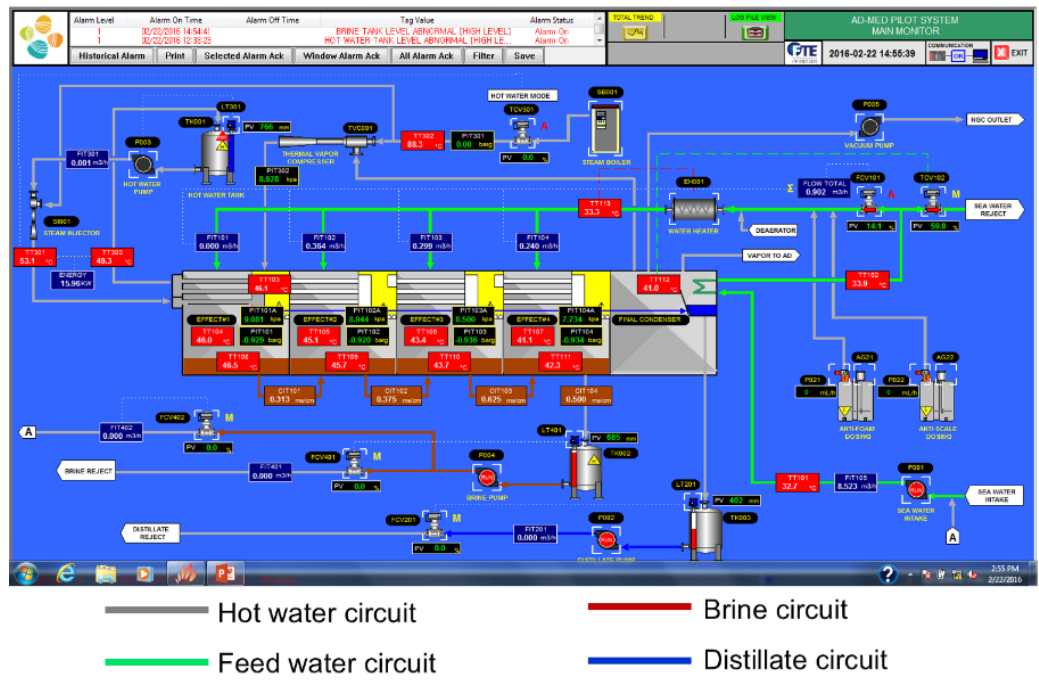

Fig. 10 (b). MEDAD pilot control (HMI) system.

Figure 11 shows the temperature profiles of all MED effects operating at $50^{\circ} \mathrm{C}$. The inter effect temperature difference was noted as $2-3^{\circ} \mathrm{C}$, same as in commercial MED plants. The condenser cooling water is supplied from Red Sea before supplying as a feed and average temperature was observed as $33^{\circ} \mathrm{C}$. After 72 hours successful operation, MED system was hybridized to AD cycle to demonstrate as MEDAD cycle. The experiment was continued for another 72 hours and temperature trends are ploted in Figure 12. It can be seen that after hybridization, the inter effect temperature difference was increased to $4-5^{\circ} \mathrm{C}$ and last effect was operating at $25^{\circ} \mathrm{C}$, below feed water temperature, as compared to conventional MED system operating at $42^{\circ} \mathrm{C}$. 


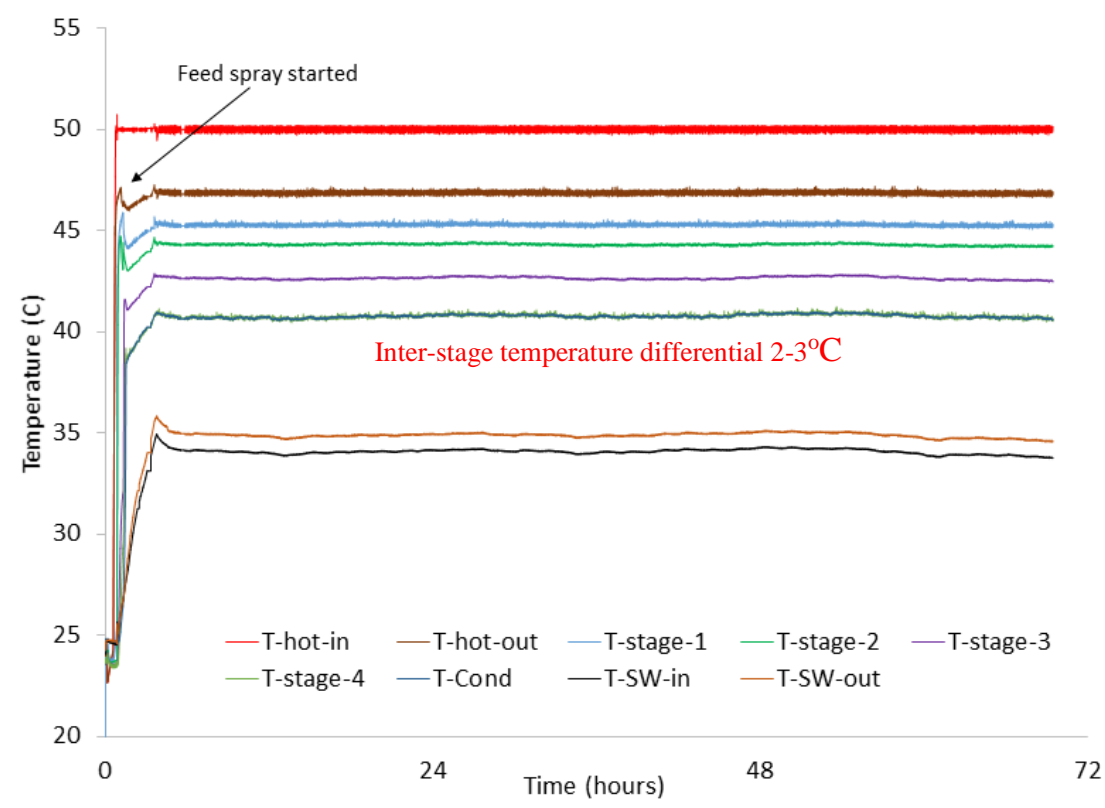

Fig. 11. 4 stages MED and condenser temperature trends at heat source $50^{\circ} \mathrm{C}$ for 72 hours operation.

The MED operation below ambient temperature is demonstrated for the first time in the desalination history. The successful operation will provide opportunity of MED system to operate from top temperature $50^{\circ} \mathrm{C}$ to last effect temperature to as low as $5^{\circ} \mathrm{C}$ as $\mathrm{AD}$ cycle can help to pull temperature to $5-7^{\circ} \mathrm{C}$ due to silica gel affinity for water vapors. This excellent thermodynamic synergy between MED and AD will not only help to extend conventional MED system operational rage for an additional recoveries but will also boost water production to almost two folds as presented in Figure 13. The two fold water production boost due to hybridization processes can be noticed clearly from the production profiles at same heat supplied conditions. 


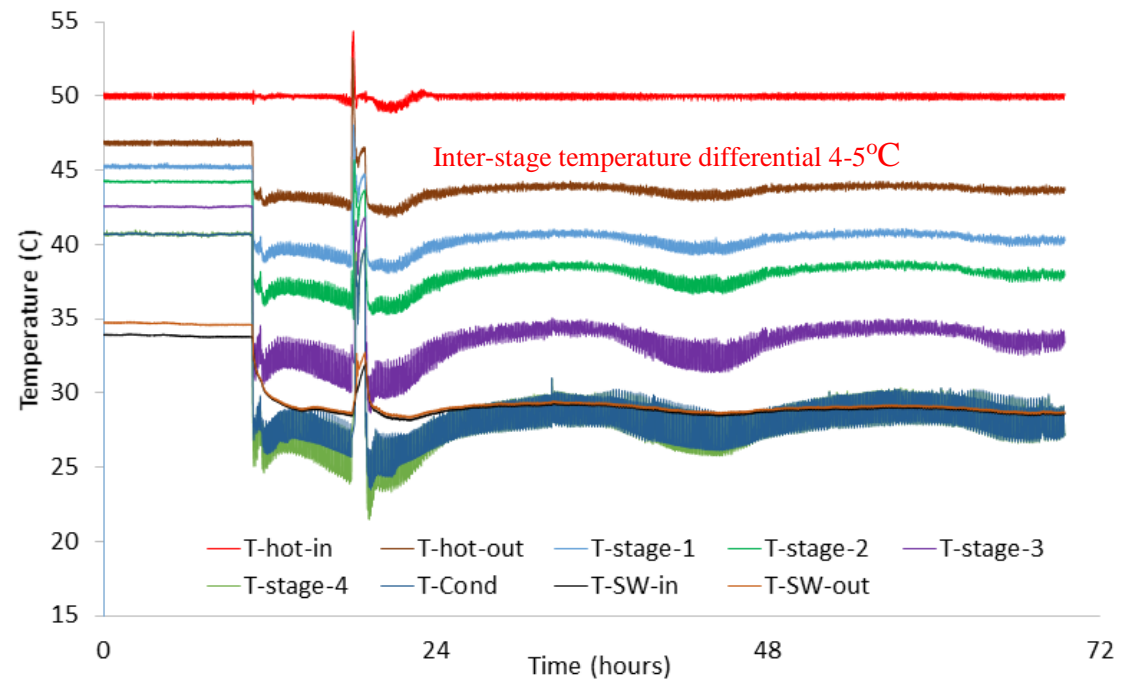

Fig. 12. Temperature profiles of MEDAD hybrid cycle effects and condenser at heat source $50^{\circ} \mathrm{C}$ for 72 hours operation.

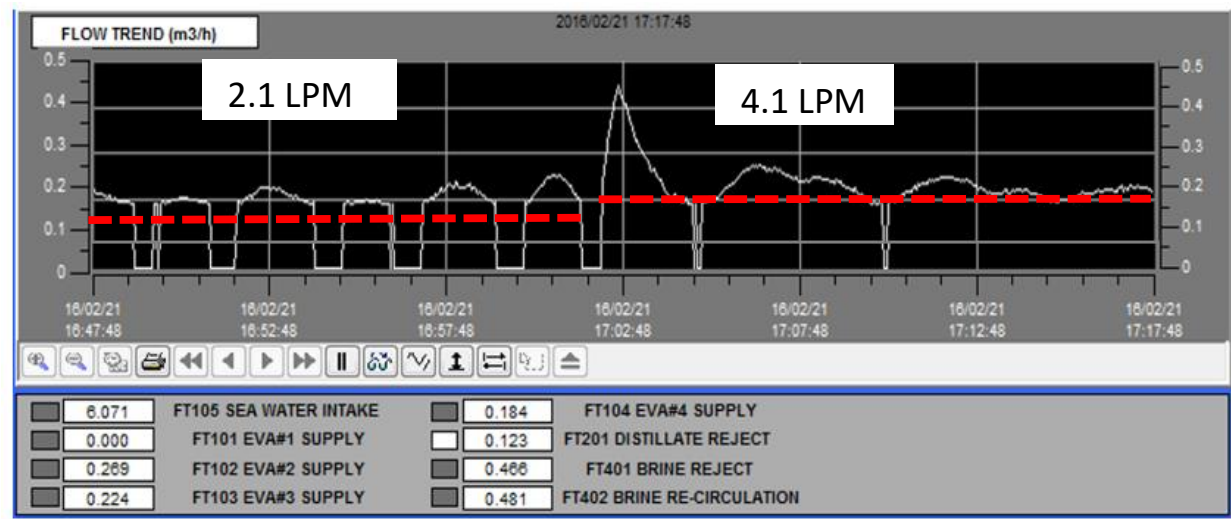

Fig. 13. Water production profiles of conventional MED and MEDAD hybrid cycle at heat source $50^{\circ} \mathrm{C}$. 


\section{Desalination Processes Performance Evaluation}

Currently, different methods are employed to evaluate diverse desalination processes. For example, thermally driven desalination processes are evaluated by performance ratio (PR) and pressure driven processes are based on specific energy consumption $\left(\mathrm{kWh} / \mathrm{m}^{3}\right)$. In industry, operators sometimes use specific energy consumption method for both processes by considering the different grade of energies as same such as electricity and low pressure steam as shown in equation 1 . This misconception of considering all energies as same grade provide distorted evaluation for different desalination processes. Since derived energies (electricity and steam) involved their generation processes efficiencies so they must be converted to primary energy before considering for evaluation processes.

$$
\begin{aligned}
& P R=\left(\begin{array}{c}
\begin{array}{c}
\text { Equivalent heat of evaporation } \\
\text { of distillate production }
\end{array} \\
\text { Energy input }
\end{array}\right) \\
& \cong \frac{2326\left\{\frac{\mathrm{kJ}}{\mathrm{kg}}\right\}}{3.6 x\left[\left\{\frac{\mathrm{kWh} h_{\text {elec }}}{\mathrm{m}^{3}}\right\}+\left\{\frac{\mathrm{kWh} h_{\text {ther }}}{m^{3}}\right\}+\left\{\frac{k W h_{\text {Renewable }}}{m^{3}}\right\}\right]}
\end{aligned}
$$

We proposed universal performance ratio (UPR) method for all kind of desalination processes evaluation a common platform because it based on primary energy. All derived energies should be converted to primary energy by considering their conversion factors and then can be utilized to calculate the performance as shown in equation 2 . The proposed method can be utilized for any processes efficiency calculation and it can be compared with any other technology because they all based on primary energy basis.

$$
\begin{gathered}
U P R \cong \frac{2326\left\{\frac{\mathrm{kJ}}{\mathrm{kg}}\right\}}{3.6 \times\left[\left\{\frac{\mathrm{kWh} \text { elec }}{\mathrm{m}^{3}}\right\} C F 1+\left\{\frac{k W h_{\text {ther }}}{\mathrm{m}^{3}}\right\} C F 2+\left\{\frac{k W h_{\text {Renewable }}}{\mathrm{m}^{3}}\right\} C F 3\right]} \\
C F=\text { conversion factor }
\end{gathered}
$$

In a cogeneration based desalination plant, detailed exergetic analysis showed that gas turbine cycle consume around $73.17 \%$ on input fuel exergy. The hear recovery steam generator help to recover $26.83 \%$ exergy from exhaust gases to produce steam for steam cycle and desalination processes. The Rankine cycle consume around $23.43 \%$ and desalination processes only utilize $3.4 \%$ on input fuel exergy. Considering these propor- 
tions, the conversion factors are calculated to convert derived energies to primary energy to compute the UPR for desalination processes as summarized in Table 1. It can be seen that MED processes performance is the highest because it has best thermodynamic synergy when combined with power plants. Most importantly, all desalination processes are operating only at $10-15 \%$ of thermodynamic limit. This shows that the current desalination processes are not sustainable and their efficiency need to improve to achieve $25-30 \%$ of thermodynamic limit to achieve future sustainability goals. High efficiency desalination processes integrated with renewable energy sources can be best choice for future water supplies [23, 24].

Table 1. Universal performance ratio comparison of all desalination processes.

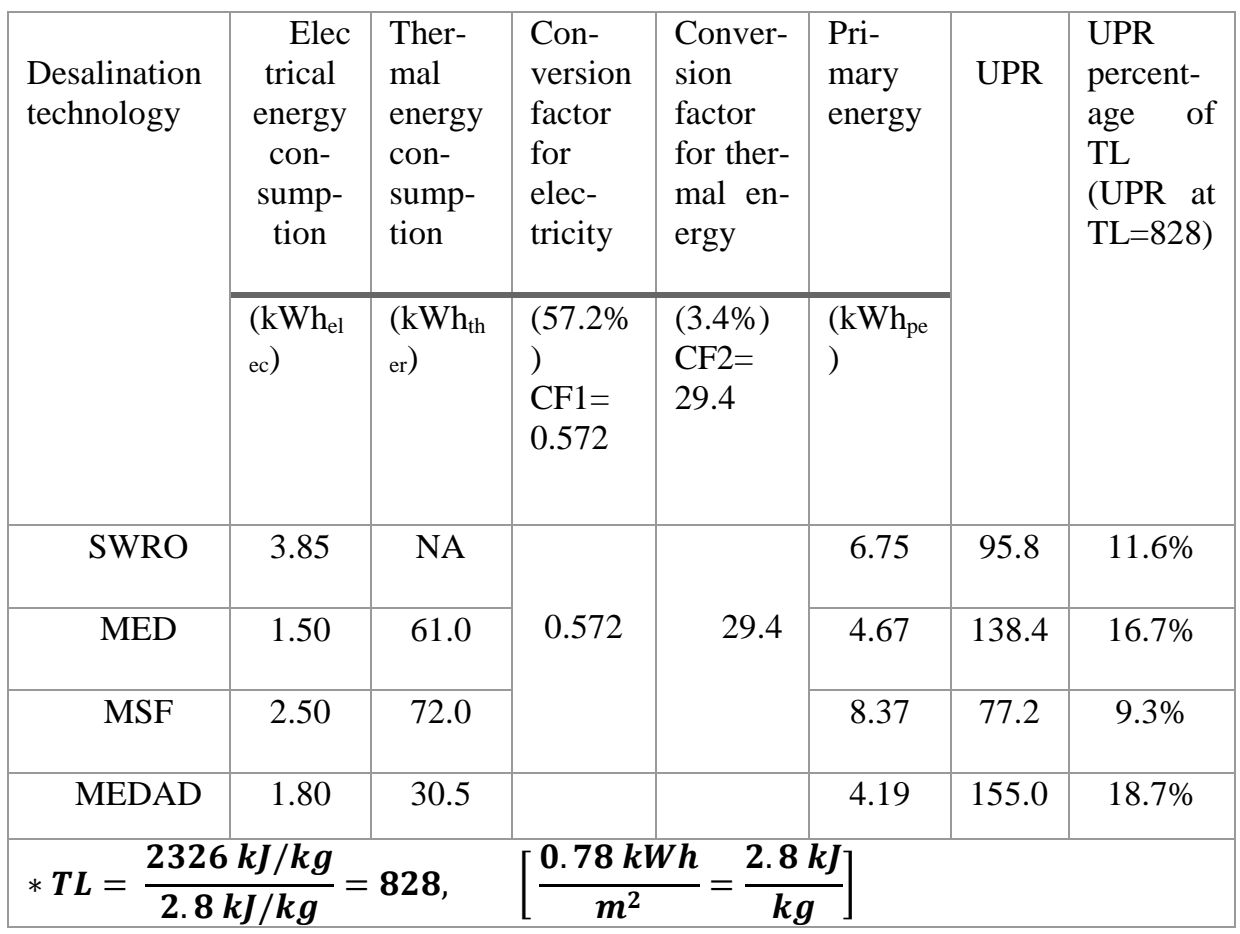

It can be seen that even with paid thermal energy, MEDAD hybrid cycle has highest UPR as compared to other processes. In case of MgO+MEDAD, the thermal energy will be free on small expense of electrical to drive circulation pumps that will boost UPR to over 200. 


\section{Conclusions}

Thermally driven desalination system and solar thermal energy storage system have been proposed for 24 hours operation. It was showed that renewable energies were not implemented at commercial scale due to intermittent nature. An efficient and reliable storage system can overcome this limitation and these free energy sources can be applied for sustainable production of desalinated water. Magnesium oxide based CHP energy storage system is proposed to supply thermal energy to hybrid MED+AD desalination system to produce desalinated water to fulfil future water demand. The desalination processes operating with renewable energy sources will not help to reduce environmental impact but also overall water production cost. These sustainable energy sources will help to fill gap between future water demand and supply in sustainable manner. The proposed system performance is successfully demonstrated at KAUST ans it is estimated to have highest UPR, over 200. These innovative solutions will help to save energy and protect environment.

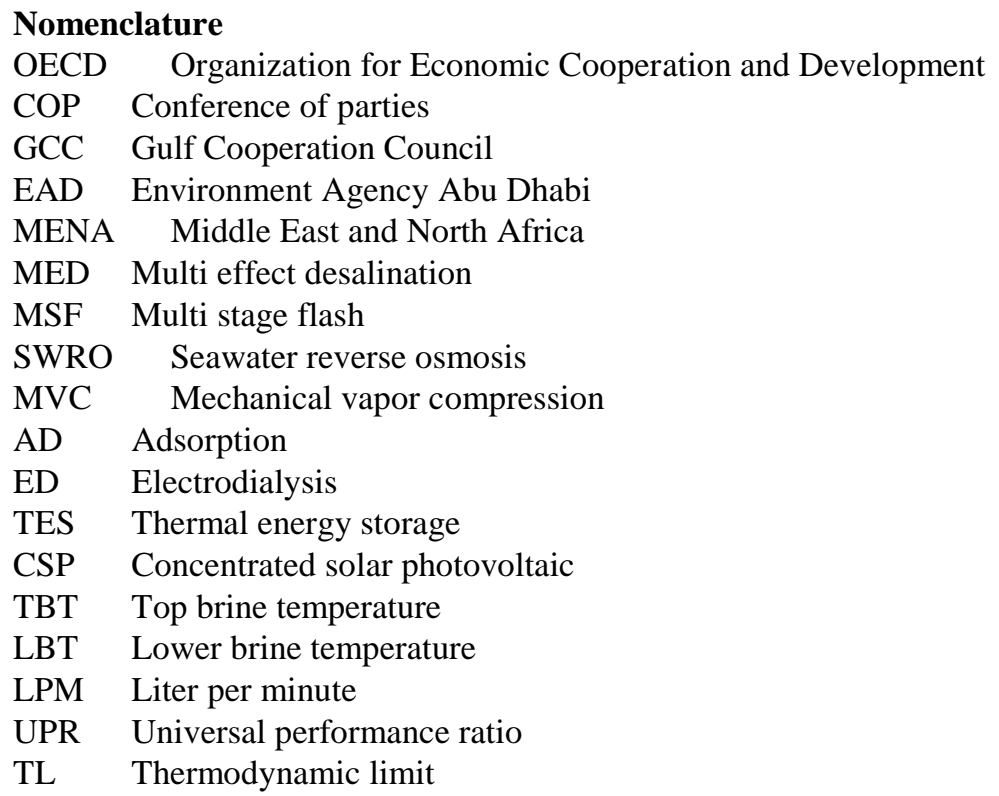

\section{References}

1. Laura Parmigiani, Water and Energy in the GCC: Securing Scarce Water in Oil-Rich Countries, A report by The Institut français des relations internationales (Ifri), ISBN: 978-2-36567-442-3 (2015).

2. Saima Munawwar and Hosni Ghedira, A review of renewable energy and solar industry growth in the GCC region, Energy Procedia 57, $3191-3202$ (2014). 
3. Renewable Energy Market analysis, The GCC Region, A report by International Renewable Energy Agency (IREA), ISBN: 978-92-95111-81-3 (2016).

4. Muhammad Wakil Shahzad, Muhammad Burhan, Li Ang and Kim Choon $\mathrm{Ng}$, Energy-water-environment nexus underpinning future desalination sustainability, Desalination 413, 52-64 (2017).

5. Mahmoud Shatat and Saffa B. Riffat, Water desalination technologies utilizing conventional and renewable energy sources, International Journal of LowCarbon Technologies 9, 1-19 (2014).

6. P. Pardo, A.Deydier, Z. Anxionnaz-Minvielle, S.Rougé, M. Cabassud and P.Cognet, A review on high temperature thermochemical heat energy storage, Renewable and Sustainable Energy Reviews 32, 591-610 (2014).

7. Kato Y, Harada N and Yoshizawa Y. Kinetic feasibility of a chemical heat pump for heat utilization of high-temperature processes, Applied Thermal Engineering 19, 239-254 (1997)

8. Kato Y, Saku D, Harada N and Yoshizawa Y, Utilization of high temperature heat from nuclear reactor using inorganic chemical heat pump, Progress in Nuclear Energy 32, 563-570 (1998).

9. Kato Y, Takahashi F, Sekiguchi T and Ryu J, Study on medium temperature chemical heat storage using mixed hydroxides, International Journal of Refrigeration 32, 661-666 (2009).

10. Kato Y, Nakahata J and Yoshizawa Y, Durability characteristics of the hydration magnesium oxide under repetitive reaction, Journal of Material Sciences 34, 475-480 (1999).

11. Kato Y, Yamashita N, Kobayashi K and Yoshizawa Y, Kinetic study of the hydration

12. of magnesium oxide for a chemical heat pump, Applied Thermal Engineering 16, 853-862 (1996).

13. Muhammad Wakil Shahzad, Muhammad Burhan, Noreddine Ghaffour and Kim Choon Ng, A Multi Evaporator Desalination System Operated with Thermocline Energy for Future Sustainability, Desalination 435, 268-277 (2017)

14. Muhammad Wakil Shahzad and Kim Choon Ng, An Improved Multi-Evaporator Adsorption Desalination Cycle for GCC Countries, Energy Technology 5, 1663-1669 (2017).

15. Muhammad Wakil Shahzad and Kim Choon Ng, On the Road to Water Sustainability in the Gulf, Nature Middle East, doi: 10.1038/nmiddleeast.2016.50 (2016).

16. Muhammad Wakil Shahzad, Kim Choon Ng and Kyaw Thu, Future sustainable desalination using waste heat: kudos to thermodynamic synergy, Environmental Science: Water Research \& Technology 2 (2016) 206-212.

17. Muhammad Wakil Shahzad, Kyaw Thu, Kim Choon Ng and Chun WonGee, Recent development in thermally activated desalination methods: achieving an energy efficiency less than $2.5 \mathrm{kWhelec} / \mathrm{m}^{3}$, Desalination and Water Treatment 57, 7396-7405 (2016). 
18. Kyaw Thu, Young-Deuk Kim, Muhammad Wakil Shahzad, Jayaprakash Saththasivam and Kim Choon $\mathrm{Ng}$, Performance investigation of an advanced multi-effect adsorption desalination (MEAD) cycle, Applied Energy 159, 469477 (2015).

19. Muhammad Wakil Shahzad, Kyaw Thu, Yong-deuk Kim, Kim C Ng, An Experimental Investigation on MEDAD Hybrid Desalination Cycle, Applied Energy 148, 273-281 (2015).

20. Kim Choon Ng, Kyaw Thu, Seung Jin Oh, Li Ang, Muhammad Wakil Shahzad and Azhar Bin Ismail, Recent developments in thermally-driven seawater desalination: Energy efficiency improvement by hybridization of the MED and AD cycles, Desalination 356, 255-270 (2015).

21. Muhammad Wakil Shahzad, Kim Choon Ng, Kyaw Thu, Bidyut Baran Saha and Won Gee Chun, Multi Effect Desalination and Adsorption Desalination (MEDAD): A Hybrid Desalination Method, Applied Thermal Engineering 72, 289-297 (2014).

22. Muhammad Wakil Shahzad, The hybrid multi-effect desalination (MED) and the adsorption (AD) cycle for desalination, Doctoral Thesis, National University of Singapore (2013).

23. Muhammad Wakil Shahzad, Muhammad Burhan, Hyun Soo Son, Seung Jin Oh and Kim Choon Ng, Desalination Processes Evaluation at Common Platform: A Universal Performance Ratio (UPR) Method, Applied Thermal Engineering 134, 62-67 (2018).

24. Kim Choon Ng, Muhammad Wakil Shahzad, Hyuk Soo Son and Osman A Hamed, An Exergy Approach to Efficiency Evaluation of Desalination, Applied Physics Letters 110, 184101 (2017). 